\title{
STRUCTURAL HEALTH MONITORING OF THE JUMA MOSQUE IN ITCHAN KALA IN KHIVA (UZBEKISTAN): LASER SCANNING COMBINED WITH NUMERICAL MODELLING
}

\author{
SHAKHZOD M. TAKHIROV ${ }^{1 *}$ AND BAKHODIR S. RAKHMONOV ${ }^{2}$ \\ ${ }^{1}$ Structures Laboratory, Civil and Environmental Engineering Department, University of California, \\ Berkeley; 337 Davis Hall, Berkeley 94720; email: takhirov@,berkeley.edu; https://ce.berkeley.edu \\ (*corresponding author) \\ ${ }^{2}$ Construction and Architecture Department, Urgench State University, 14, Khamid Olimjon Str., \\ Urgench, 220100 \\ email: rah-bahodir@yandex.com; https://urdu.uz/en
}

Keywords: Heritage Structure, Brick Masonry, On-demand Monitoring, Noncontact Inspection, Laser Scanning, Point Clouds, Finite Element Modelling, Ambient Vibration Study, Material Testing, Structural Health Monitoring.

\begin{abstract}
This paper highlights the main objectives and some of the results of an extensive structural health monitoring (SHM) project begun in Khiva, Uzbekistan. The research team consists of experts from the University of California, Berkeley (Berkeley, USA) and Urgench State University (Urgench, Uzbekistan). According to archaeological data, the city of Khiva was established approximately 1500 years ago. The project started from Itchan Kala, the walled inner town of the city of Khiva. This paper describes results obtained for the Juma Mosque located inside of Itchan Kala. A continuous SHM became essential to ensure its preservation for humanity because a few structural anomalies were reported in the past. The ongoing project consists of three major phases. First, a terrestrial laser scanning (TLS) was deployed to capture and monitor anomalies of the monument's geometry in $3 D$. A laser scanner was used, and the monument's geometry was captured as a collection of points, which is called a "point cloud". Second, there is a plan to monitor the monument by in-situ measurements conducted by accelerometers, position transducers and thermocouples in the next phase. The high-sensitivity accelerometers will be used to study the resonant frequencies due to the ambient vibrations. The position transducers and thermocouples will be used for measuring the thermal expansion and retraction of the monument's minaret. They will also be used for monitoring the crack openings. Third, a finite-element (FE) model based on the as-found geometry of the point cloud will be generated. Its calibration will be based on the collected data to ensure acceptable correlations with the results of the conventional measurements. The FE model will be used for future restoration efforts to evaluate the performance and efficiency (if any) of the proposed restoration measures. This paper focuses on the results obtained for the Juma Mosque's minaret. It discusses the major findings of the laser scanning project and estimates the minaret's residual inclination and its taper. The paper shows that the minaret can be approximated by a truncated cone. A preliminary FE model of the minaret was developed, which will be updated based on the results of the upcoming ambient vibration study.
\end{abstract}




\section{INTRODUCTION}

The paper discusses results of the ongoing educational and research program in Uzbekistan. The main objective of the program is to train local engineers on the utilization of the modern tools of structural health monitoring. It consists of an extensive theoretical course and two hands-on projects. The projects to be conducted at a historic site in the ancient city of Khiva. The first project was focused on the utilization of a terrestrial laser scanner for capturing the asfound geometry of a heritage building. The second hands-on project was aimed at the utilization of conventional instruments typically used for in-situ measurements. The theoretical course and the first hands-on project have been completed. The hands-on training on the practical application of conventional instruments is scheduled for Spring 2021. This educational and research program was conducted in collaboration with the faculty and students of Urgench State University in Uzbekistan. The results of the laser scanning project and the preparatory activities for the second hands-on project are discussed herein.

Juma Mosque, a heritage structure in the inner city of Itchan Kala (Khiva, Uzbekistan), was selected for both practical projects. It was studied by many authors (see [1,2, and 3] as representative examples), but there is the first time laser scanning was used. Figure 1a shows a top view of the monument taken from Google maps and Figure 1b shows a plan view of the historic monument reproduced from [1].
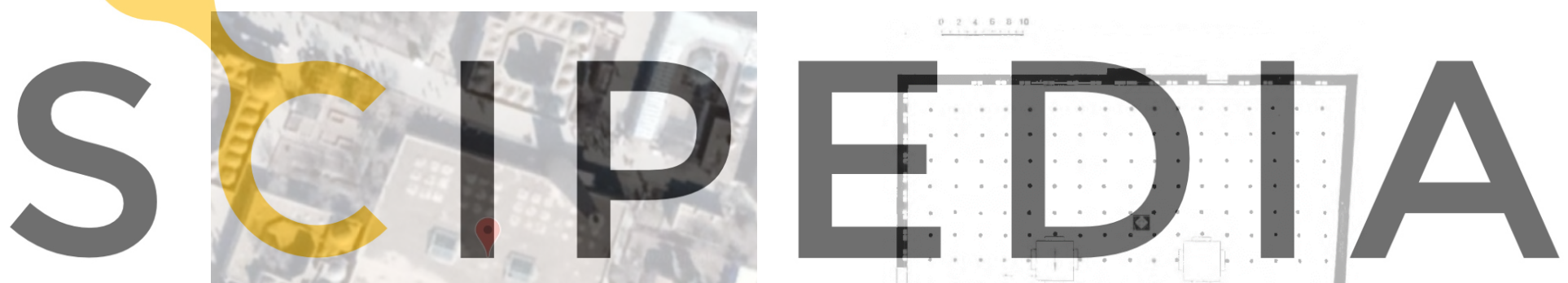

Register for free at https//Www.scipedia.com to download the version without the watermark

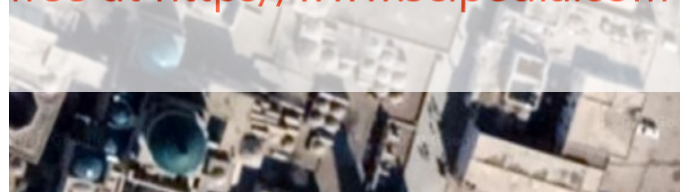

a) Image from Google maps

Figure 1: Juma Mosque

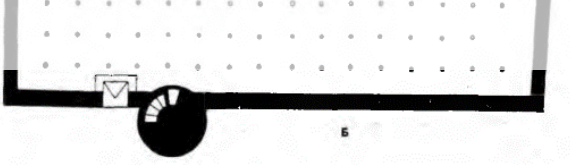

b) Plan view after [1]

As can be seen from the images, Juma Mosque is comprised of a courtyard surrounded by four walls and a minaret integrated in its north wall. The courtyard's wooden roof is supported by numerous columns.

\section{LASER SCANNING}

A terrestrial laser scanner C10 from Leica Geosystems [4] was used to collect the point clouds of the heritage structure. The point clouds were collected from eleven positions of the laser scanner, the so-called stations. Eight stations were set at ground level around the walls and three stations were set on the roof. The point clouds collected from all the stations were 
stitched together into one point cloud, the so-called registration. The manipulation of the point clouds including their registration was conducted in Cyclone from Leica Geosystems [5]. The point clouds were exported in an ASCII format for further analysis in Matlab [6]. The final registration of all stations is presented in Figure 2. It shows the monument in its natural colors and in the intensity of the returned laser beam shown in the left and right images, respectively. In addition to the laser scans, $\mathrm{C} 10$ takes images with a built-in still imaging camera. The colors captured by the camera are used for coloring the point clouds collected by the laser scanner. The natural coloring of the point cloud is quite dark because the scans were conducted on a cloudy day with very limited sunlight and, because a few scans were done right before, during and right after sunset.

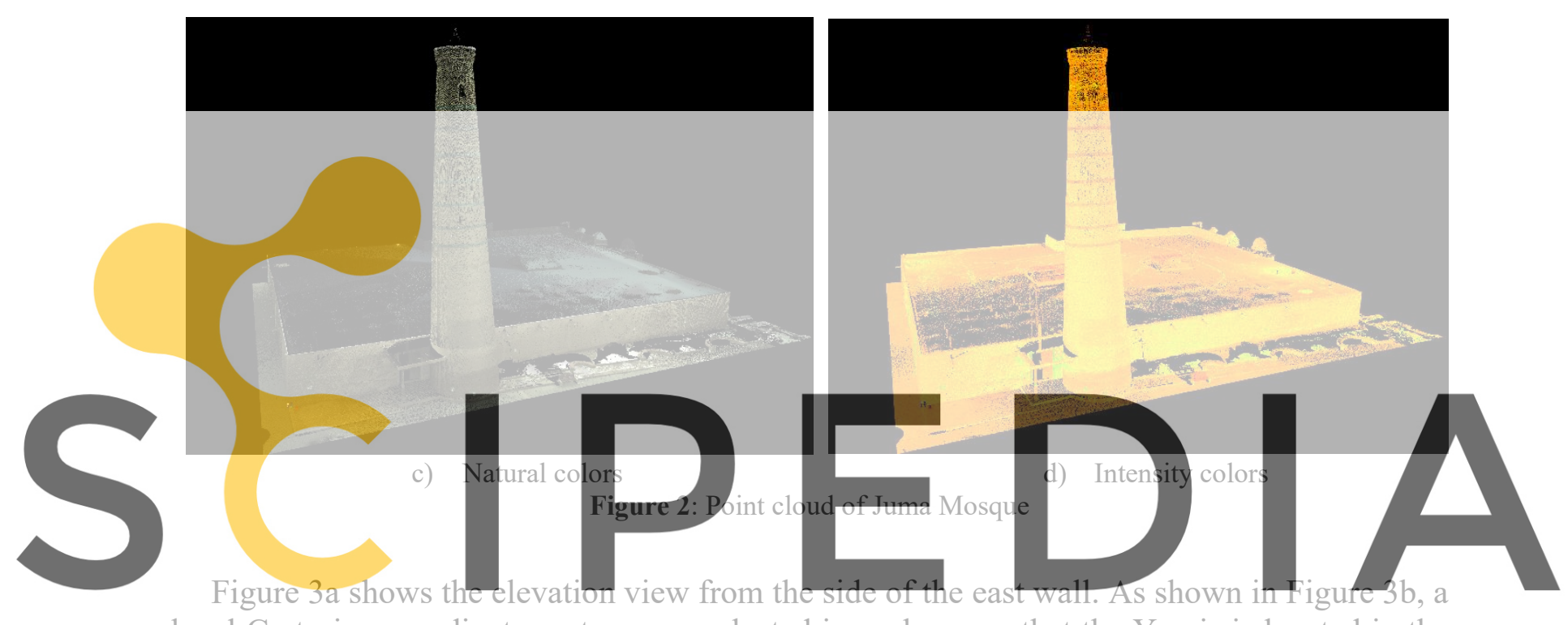

local Cartesian coordinate system was selected in such a way that the $\mathrm{Y}$ axis is located in the

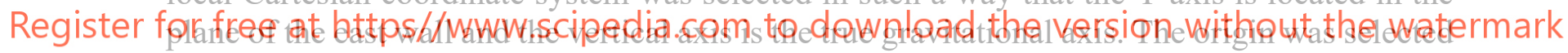

at the lowest point of the intersection of the east and north walls.

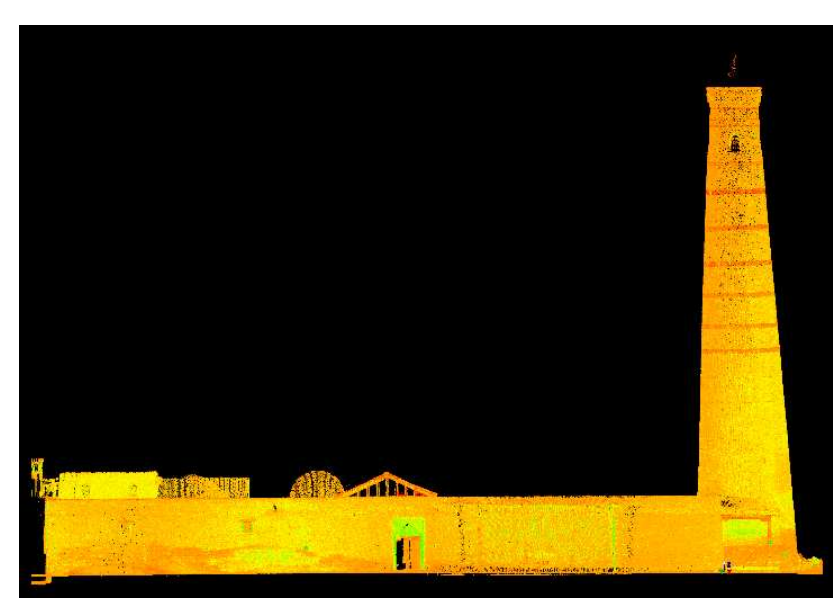

a) Elevation view: east wall side

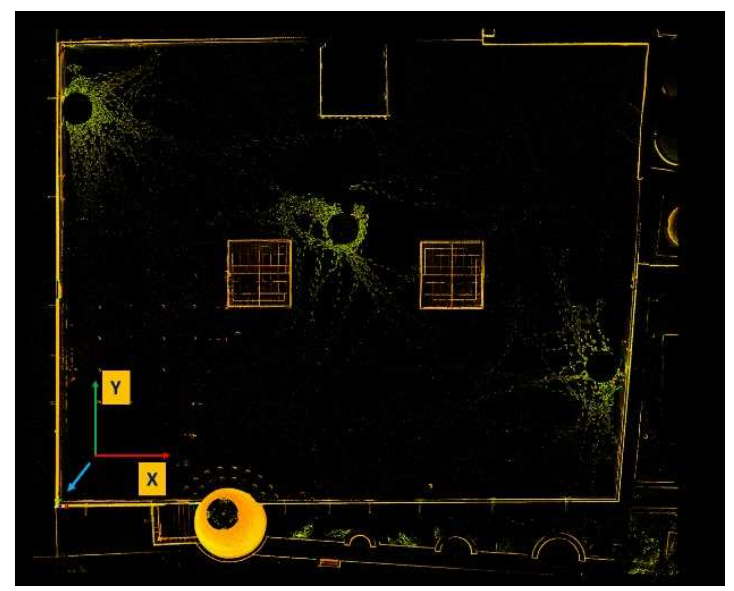

b) Local coordinate system

Figure 3: Elevation view and local coordinate system of Juma Mosque 


\section{ANALYSIS OF MINARET'S POINT CLOUD}

The details on how the laser scanning was conducted and some of the results of the preliminary analysis of the point cloud are discussed in [7]. This paper focuses on the minaret in greater detail. The minaret was studied in the following way. A number of horizontal sections were introduced which were incrementally increased from the bottom of the minaret to its top as presented in Figure 4a. The point clouds of the sections were best fit to circles. The application of the best fitting procedure resulted in two major parameters. First, a radius of the circle was estimated as the minaret's radius at each elevation. Second, a center of the circle representing a location of the minaret's axis at each elevation was calculated. Two examples of the sections' point clouds and their respective best fit circles are presented in Figure 4b. They show the section of the minaret at the bottom and the smallest section on the top. The blue dots correspond to the point clouds and the red dashed circles are the corresponding best fit circles. The green crosses show the centers of the sections. The red arrow shows the direction and the value of the minaret's drift measured between these two sections.
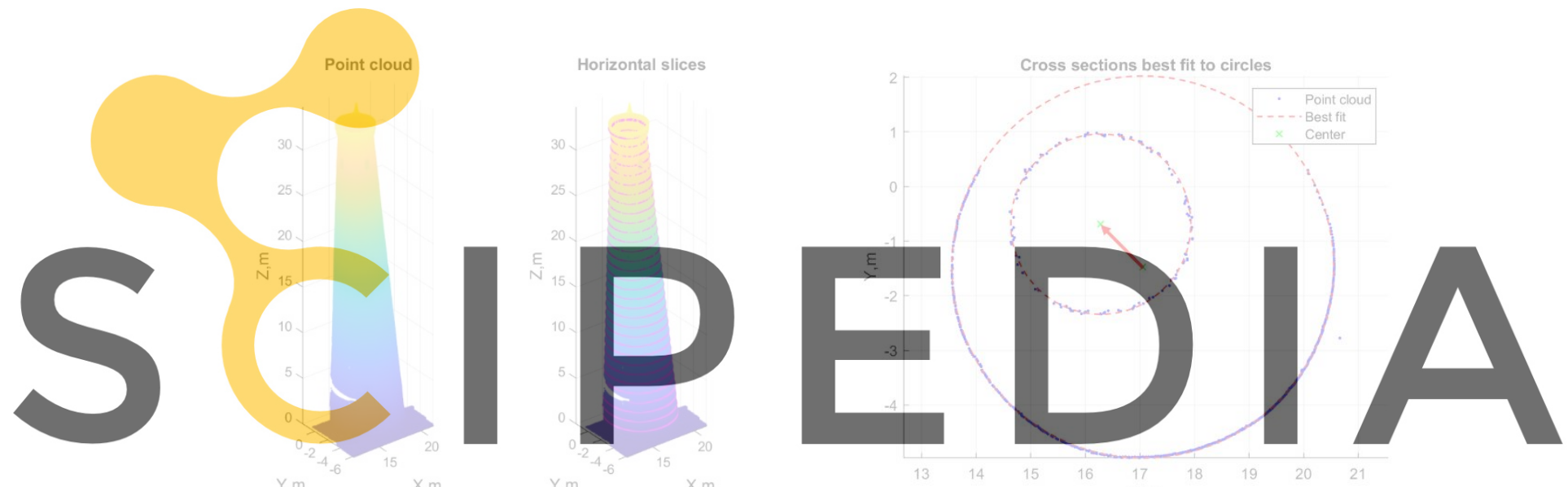

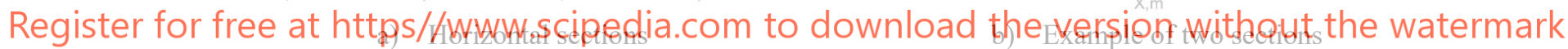
Figure 4: Global inclination of the Juma Mosque based on horizontal sections

A plot showing center point locations of all sections in presented in Figure 5a. The red crosses correspond to the centers and the blue dashed line is the least square approximation of the center points. The green arrow shows the overall direction of the inclination. As presented in this image, it is estimated to be about 46.4 degrees to the negative branch of the $\mathrm{X}$ axis. A plot showing the location of the centers in the plane of the maximum inclination in respect to the cross-section's elevation is presented in Figure 5b. The centers are shown as red crosses and the green dashed line is the least square approximation of these center points. Based on the plot, the following can be concluded. First, the center points are very close to an inclined straight line, which means that the inclination of the minaret is most likely related to the rigid body rotation of the minaret's whole structure. Second, the overall inclination is estimated as 2.15 degree including the $2 \mathrm{~m}$ deep foundation. Third, the maximum inclination from the true gravitational vertical axis is estimated as a $1.378 \mathrm{~m}$ inclination at the very top of the minaret.

Figure 6a shows the variation of the section's radius over the elevation of the minaret. Based on this plot, the original taper of the minaret was estimated. It is based on the best square 
approximation of the radii with respect to the elevations.

The inclination measured in this project was compared to that conducted by other means in 1997 and 1998 [3]. The difference between the 1997 and 1998 measurements was close to $0.05 \mathrm{~m} \mathrm{[3]}$, which corresponds to $50 \mathrm{~mm} /$ year. Based on the measurements of this project, the inclination slowed down but remains at about $11 \mathrm{~mm} /$ year on average for 23 years as presented in Figure 6b. A subsequential laser scanning project is needed to monitor a progression of the minaret's inclination.
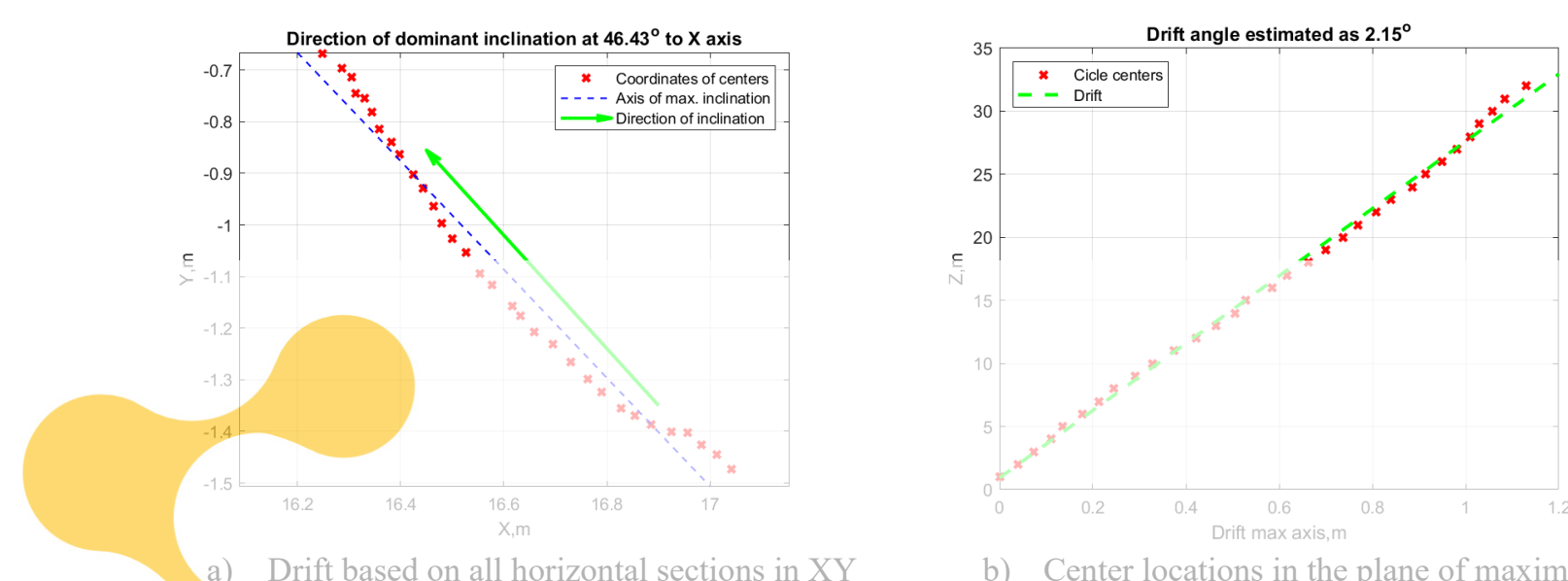

a) Drift based on all horizontal sections in XY

b) Center locations in the plane of maximum
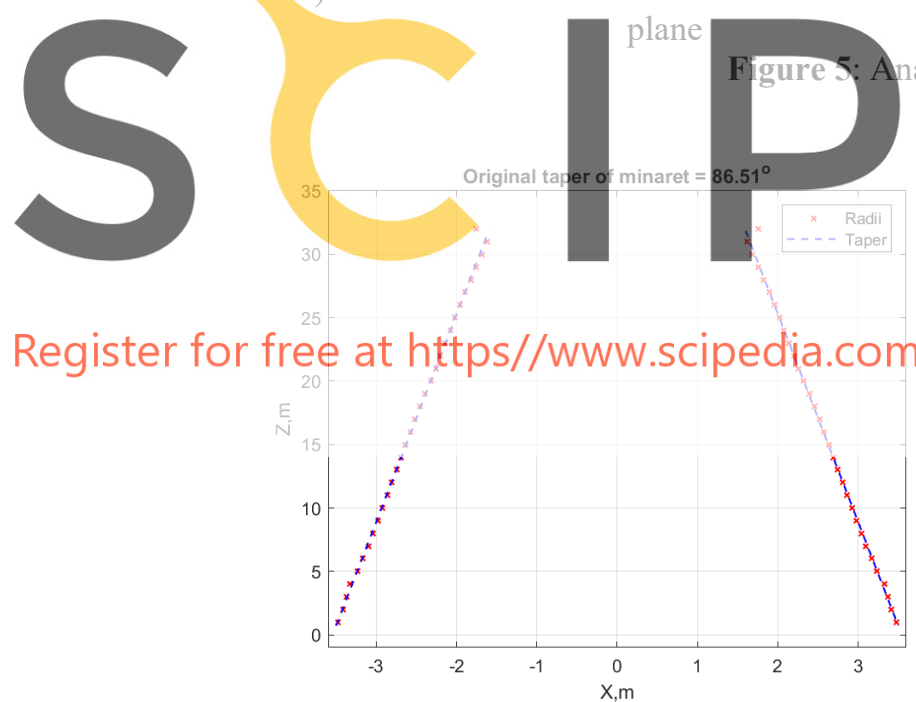

a) Radius versus elevation: taper estimate

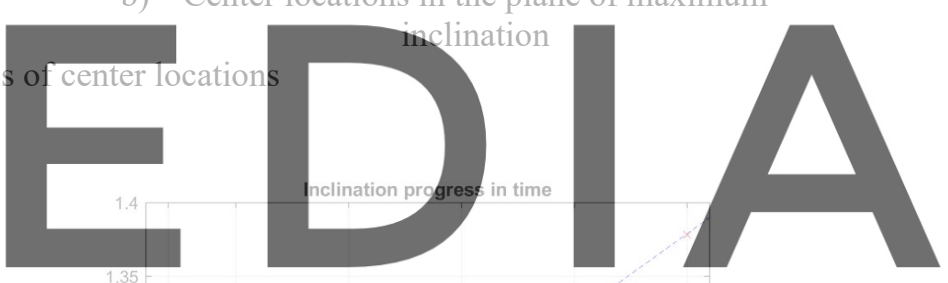

Register for free at https//www.scipedia.com to download the version without the watermark

Figure 6: Taper estimate and inclination monitoring in time

\subsection{Minaret's Exterior Surface}

Since the point clouds were collected from many stations including both on the ground and on the roof positions, the minaret's external surface was almost completely covered. The outer surface of the minaret was unwrapped in order to study the locations of the openings and the elevation and width of strips made of blue colored tiles as presented in Figure 7a. To achieve that for each point, an angle of a polar coordinate system based on $\mathrm{X}$ and $\mathrm{Y}$ coordinates was 
calculated in order to estimate a correlation between the $\mathrm{Z}$ coordinate of each point and its polar angle. The surface was unwrapped along the line where the polar angle is equal to 180 degrees (shown by the magenta line in Figure 7a). The red arrows show the unwrapping direction and the plane right next to the minaret shows the plane on which the unwrapped surface is projected. The resultant relationship between the polar angle and the elevation is shown in Figure 7b. It is worth noting, that prior to these calculations the minaret's inclined axis was assigned to the vertical $\mathrm{Z}$ axis. In other words, the inclination of the minaret was removed to come up with this unwrapped image of the minaret's surface. It shows four large openings on the minaret's top and a number of smaller openings at other elevations. It also shows seven blue colored strips assembled from blue tiles, which start from an elevation of about 14 meters. The elevation of each strip is summarized in Table 1. They were estimated based on the changes in the RedGreen-Blue (RGB) coloring of the surface at a narrow strip around -140 degrees. Because of the size limitations of this paper, only the final result is presented herein without a detailed discussion on how it was conducted.
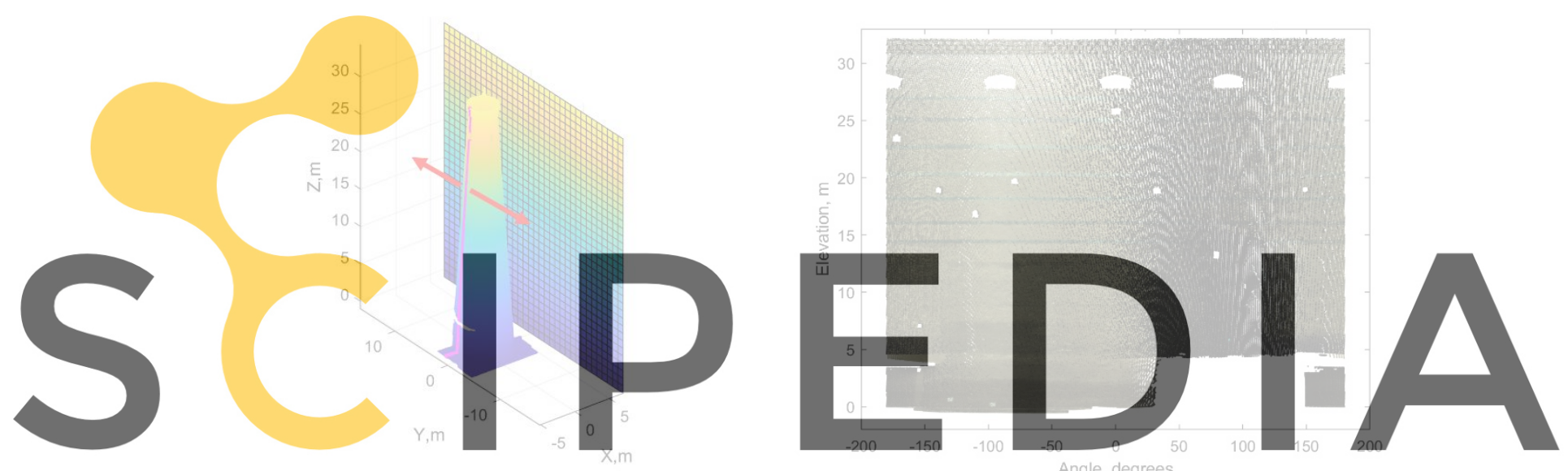

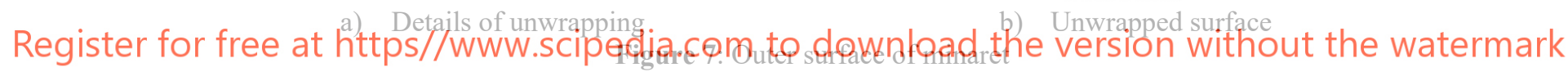

Table 1: Elevation of each blue colored strip

\begin{tabular}{cc}
\hline Strip numbering & Elevation, m \\
\hline Strip 1 & 13.87 \\
\hline Strip 2 & 15.86 \\
\hline Strip 3 & 17.93 \\
\hline Strip 4 & 20.09 \\
\hline Strip 5 & 22.46 \\
\hline Strip 6 & 24.85 \\
\hline Strip 7 & 26.72 \\
\hline
\end{tabular}

\subsection{Approximation by Truncated Cone}

The minaret was approximated by a truncated cone. It was conducted for the minaret, in which the inclined axis was forced to coincide with the vertical axis. The cone was based on the diameters of the best fit circles at the bottom of the minaret and its narrowest cross section 
on top. The 3D representation is presented Figure 8a. This image shows two views of the point clouds and the truncated cone. The left 3D image shows a view toward the positive direction of the $\mathrm{X}$ axis and the right $3 \mathrm{D}$ image shows a view toward the positive direction of the $\mathrm{Y}$ axis. The deviations of the minaret from the truncated cone are presented in Figure 8b. They show the deviations on the unwrapped exterior surface of the minaret. As presented in the latter image the deviations from the truncated cone remain within $\pm 0.15 \mathrm{~m}$ and as such it was utilized in the finite element modelling discussed below.
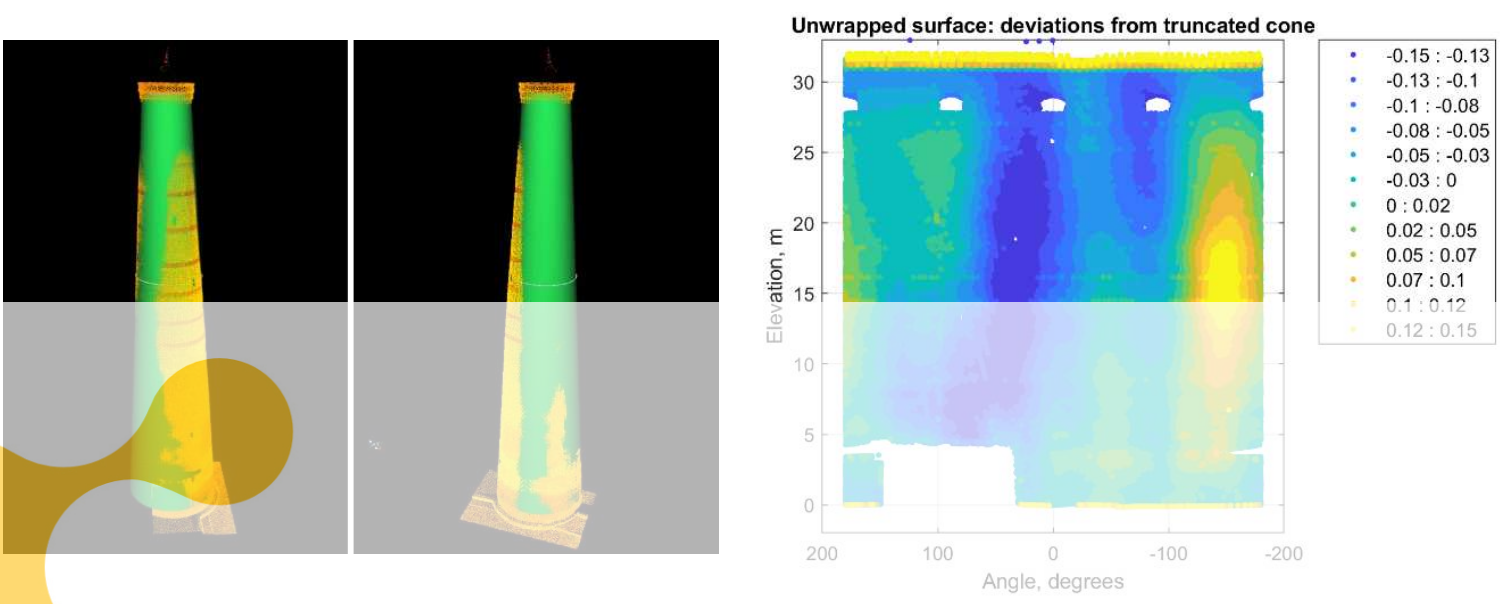

c) Approximation by cone (green): two
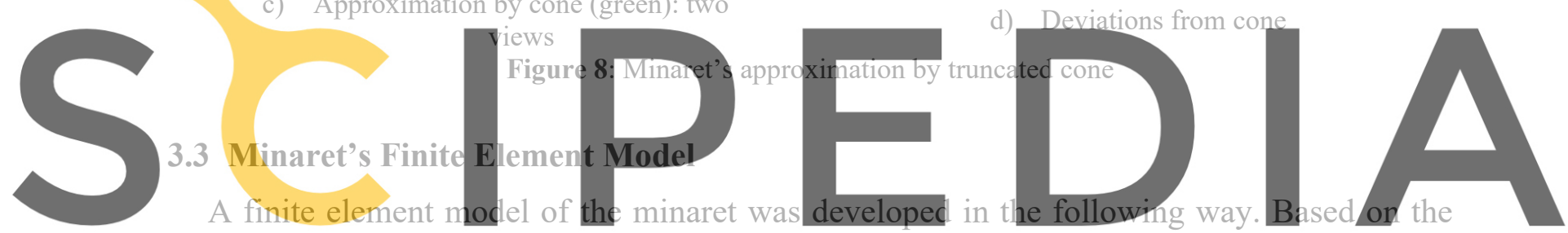

design of typical minarets in Uzbekistan, the minaret was assumed to consist of a brick masonry

Register for

shell. Material properties were based on tests of a sample brick $[8,9]$. The truncated cone discussed above was selected as an outer surface of the minaret. The radius of the core and the

thickness of the wall at each elevation was obtained in the following way. It was assumed that the ratios of the minaret's radius to the radius of the core and the thickness of the wall remain the same as those measured in the Islom Khodja minaret which was studied in [10]. It was also assumed that the core's participation can be neglected, especially in the case of very small amplitude vibrations which typically occur in an ambient vibration study. In addition, the participation of the staircase is also assumed to be negligible. These assumptions are acceptable for a preliminary estimate of the resonant frequency of the minaret, which will be evaluated in the ambient vibration studies scheduled for Spring 2021.

The minaret was modelled in SAP2000 [11] by utilizing solid elements as presented in Figure 9. The meshes at the bottom and top cross sections are shown in Figure 9a. A complete model of the tapered minaret with the wall thickness changing over the elevation is presented in Figure 9b.

Although the brick material was tested in the past, the effective Young modulus of the minaret will be much lower than that [12]. This is related to the fact that the brick masonry wall consists of the bricks and the mortar between the bricks and, the Young modulus of the mortar 
is much lower than that of the brick. To address this, the effective Young modulus was taken as $3.0 \mathrm{GPa}$. The density of the brick masonry was assumed to be $1,600 \mathrm{~kg} / \mathrm{m} 3$. The Poisson's ratio was assumed as 0.2. Based on these assumptions, the first resonant frequency was estimated at $2.1 \mathrm{~Hz}$. It is much greater than the resonant frequency of a minaret in Turkey built of stone masonry [13]. The first resonant frequency of the latter minaret of about the same height was estimated as $0.71 \mathrm{~Hz}$. This can be related to the fact that the minaret in Juma Mosque is tapered and the thickness of the wall is much greater than that of the stone masonry minaret in Turkey. In the Juma Mosque's minaret the wall thickness at the bottom and the top were assumed as $1.2 \mathrm{~m}$ and $0.64 \mathrm{~m}$, respectively. The stone masonry minaret had almost no taper and the wall thickness varied from $0.36 \mathrm{~m}$ to $0.18 \mathrm{~m}$.

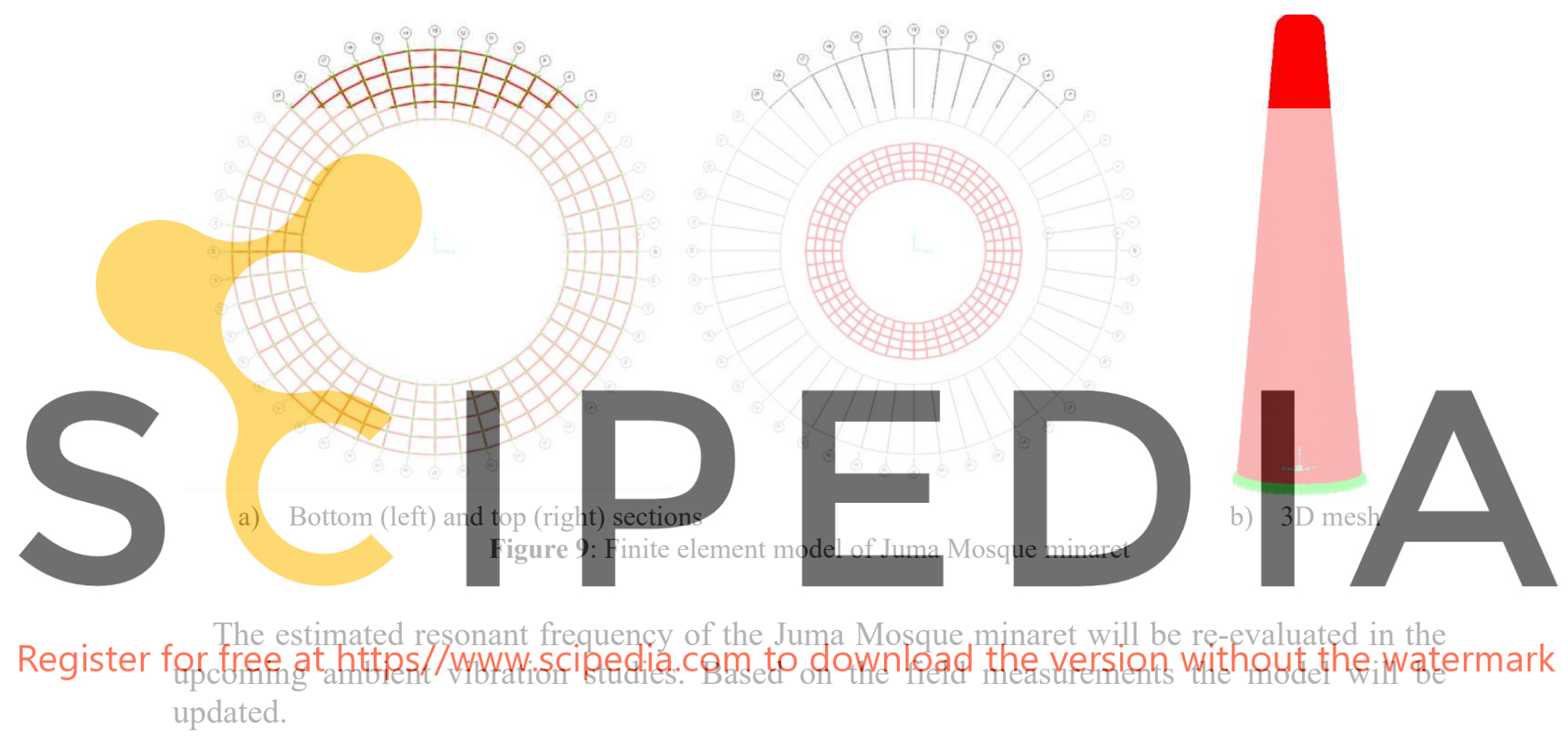

\section{CONCLUSIONS}

- A large residual inclination of a minaret in the Juma Mosque monument was measured by the terrestrial laser scanner. This inclination is evenly distributed over the elevation of the monument which is evidence that it is related to a rigid body rotation of the minaret's body.

- Based on a comparison of the recently obtained measurements to those reported earlier, it is concluded that the inclination is progressing, and it has increased by $270 \mathrm{~mm}$ since 1997. A continuous monitoring of this inclination is crucial for the structural integrity of the minaret and for finding a mitigation measure to slow its increase.

- $\quad$ Resonant frequency of the minaret's preliminary finite element model is greater than that of a stone masonry minaret with a much smaller wall thickness. The model will be updated after the ambient vibration study to be conducted in 2021.

Acknowledgements. The project would not be possible without funding provided by the 
Central Asia University Partnerships Program (UniCEN). UniCEN is sponsored by the U.S. Embassy in Tashkent, Uzbekistan and administered by American Councils for International Education. The registration fee of the paper was sponsored by University of California, Berkeley (UC Berkeley), which is greatly appreciated. Special thanks are due to Mr. Brian Quigley of BNZ, Uzbekistan for providing access to a terrestrial laser scanner. The authors would like to acknowledge the Delta Group Max, Uzbekistan for logistical and technical support provided for the laser scanning project. Special thanks are due to Holly Halligan of UC Berkeley for editing the paper.

\section{REFERENCES}

[1] Mankovskaya, L., Bulatova, V. Monuments of the architecture of Khorezm. Uzbekistan: Gafur Gulyam Publishing House. 162 p. 1978 (in Russian).

[2] Durdieva, G., Davletov, B. Results of Technical Condition's Monitoring Conducted in Itchan Kala: Juma Mosque. 2008 (in Uzbek).

[3] Abdurashidov, K., Kabulov, F., Rakhmanov, B. Engineering Problems of Architectural Monuments. "Fan" publishing house of Academy of Sciences of Republic of Uzbekistan, Tashkent, 2011 (in Russian).

[4] Leica Geosystems AG (2011). Leica ScanStation C10. https://w3.leicageosystems.com/downloads $123 / \mathrm{hds} / \mathrm{hds} / \mathrm{ScanStation} \% 20 \mathrm{C} 10 /$ brochures-

datasheet/Leica_ScanStation_C10 DS en.pdf.

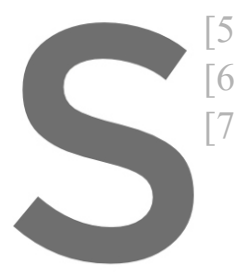

Leica Geosystems (2018). Cyciono Version 9.2.1.

6] MathWorks (2016).

Takhirov, S., Rakhn

$\mathrm{J}$. and Takhirov,

Uzbekistan by Lase

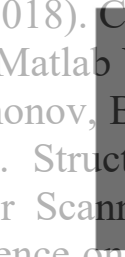

Version R2016
B., Nafasov, R.
ctural Health
nning. Submitte
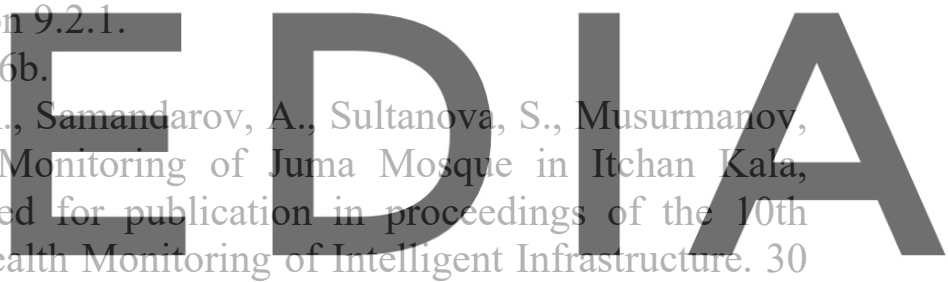

June - 2 July, 2021, Porto, Portugal.

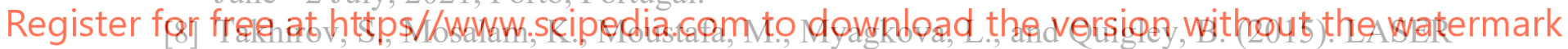

SCANNING, MODELING, AND ANALYSIS FOR DAMAGE ASSESSMENT AND

RESTORATION OF HISTORICAL STRUCTURES. COMPDYN 2015. 5th ECCOMAS Thematic Conference on Computational Methods in Structural Dynamics and Earthquake Engineering. M. Papadrakakis, V. Papadopoulos, V. Plevris (eds.). Crete Island, Greece, 25-27 May 2015.

[9] Takhirov, S., Gilani, A., Quigley, B., and Myagkova, L. (2018). Structural Health Monitoring and Assessment of Seismic Vulnerability of Historic Monuments on the Great Silk Road Based on Laser Scanning. The International Conference on Structural Analysis of Historical Constructions (SAHC 2018). 2254-2263. September 11-13, 2018, Cusco, Perú.

[10] Rakhmanov, B. Engineering analysis of the design features of the Islom Khoja minaret. A paper in preparation for publication.

[11] Computers and Structures, Inc. (CSI), 2014. SAP2000. Ultimate Version 16.1.1. Structural Analysis Program.

[12] Sayari Arash. MECHANICAL PROPERTIES OF MASONRY SAMPLES FOR THEORETICAL MODELING. 15th International Brick and Block Masonry Conference 
Florianópolis , Brazil, 2012.

[13] Dogangun, A, Acar, R, Sezen, H, Livaoglu R. Investigation of dynamic response of masonry minaret structure. Bulletin of Earthquake Engineering, August 2008, DOI 10.1007/s10518-008-9066-5.
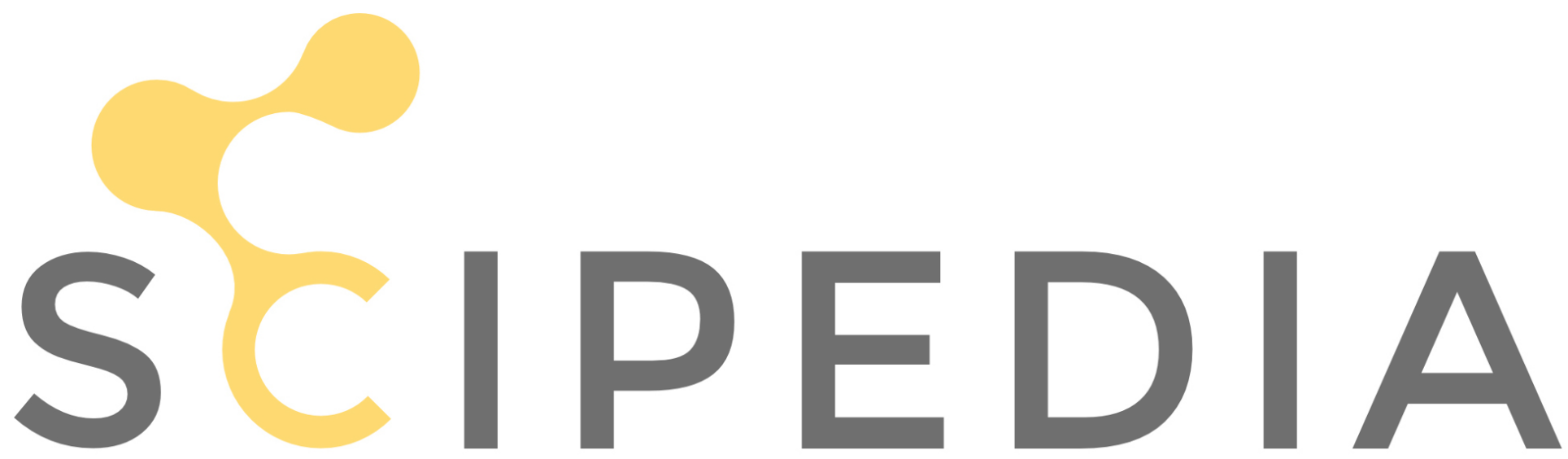

Register for free at https//www.scipedia.com to download the version without the watermark 